\title{
Avant-propos. ICOFOM Study Series : notre héritage, notre tradition
}

\section{Bruno Brulon Soares}

\section{(2) OpenEdition}

1 Journals

\section{Édition électronique}

URL : http://journals.openedition.org/iss/1956

DOI : $10.4000 /$ iss. 1956

ISSN : 2306-4161

Éditeur

ICOM - International Council of Museums

\section{Édition imprimée}

Date de publication : 1 août 2020

Pagination : 9-10

ISBN : 978-2-491997-11-3

ISSN : 2309-1290

\section{Référence électronique}

Bruno Brulon Soares, «Avant-propos. ICOFOM Study Series : notre héritage, notre tradition », ICOFOM Study Series [En ligne], 48-1 | 2020, mis en ligne le 01 août 2020, consulté le 24 septembre 2020. URL: http://journals.openedition.org/iss/1956 ; DOI : https://doi.org/10.4000/iss.1956 


\section{Avant-propos}

\section{ICOFOM Study Series : notre héritage, notre tradition}

Cette édition des ICOFOM Study Series est une invitation à porter une réflexion critique sur le passé de la muséologie, en examinant les traditions que nous souhaiterions confier aux générations futures de muséologues et de professionnels des musées. Le sujet proposé, «Le futur de la tradition en muséologie », est notre interprétation de la thématique principale de la $25^{\mathrm{e}}$ Conférence Générale de l'ICOM à Kyoto (Japon), où ICOFOM a organisé plusieurs ateliers au cours desquels ont été présentées les communications à la base des contributions de ce numéro. La Conférence elle-même, où le futur des musées et de la définition de l'ICOM ont été largement débattus, s'est avérée être un événement historique qui sera transmis au futur en tant que part de la tradition de l'ICOM au XXI ${ }^{e}$ siècle.

Cependant, les changements ne sont jamais aisés, en ce qu'ils impliquent des renégociations du passé dans le présent. La Conférence Générale de Kyoto a été perçue par beaucoup d'entre nous comme un moment d'importants conflits entre différentes visions du musée qui peuvent apparaitre comme annonciateurs des changements à venir concernant les valeurs et déclarations d'intention qui ont guidé l'organisation dans son existence au cours des décennies précédentes. Immergés dans la culture japonaise, qui embrasse la tradition tout en avançant vers le futur, nos débats à Kyoto seront remémorés en tant que part essentielle de notre histoire partagée et donnent le ton pour les futures réflexions menées dans cette revue et d'autres forums internationaux.

En prenant la responsabilité de poursuivre la transmission des théories muséologiques et des études sur le musée pour le présent et pour le futur, j'ai accepté, à Kyoto, le rôle de rédacteur des ICOFOM Study Series dans le souci d'honorer le travail des rédacteurs précédents, Ann Davis et François Mairesse, auprès de qui j'ai tant appris au cours des années précédentes en tant qu'auteur, membre d'ICOFOM et muséologue. Cette revue, créée en I983 par le Président d'ICOFOM Vinoš Sofka à un autre moment de réinvention de la muséologie, est l'héritage des générations précédentes à la mienne et celles à venir. Et si la muséologie est notre patrimoine immatériel - selon François Mairesse dans son introduction à cette édition -, alors les ICOFOM Study Series sont le moyen d'assurer sa conservation et sa transmission pour le futur.

Ce numéro I du volume 48 marque le début d'une nouvelle ère éditoriale pour les ICOFOM Study Series, avec l'intention de développer cette revue par le bais de la publication de deux numéros chaque année. Ce défi est rendu possible 
uniquement grâce au rude travail d'un groupe très engagé de contributeurs, dont font partie des membres de notre nouveau Bureau éditorial, des paires évaluateurs anonymes et des membres d'ICOFOM qui dédient leur temps à ce journal pour le travail d'organisation, d'édition, de relecture et de correction des articles. La transmission de notre héritage est seulement possible grâce à ces personnes qui transmettent nos traditions avec cour et passion. Je leur en suis profondément reconnaissant.

Bruno Brulon Soares 